\title{
M. KUCZYNSKI-GODARD (1890-1967): FOTOGRAFÍAS MÉDICO- ANTROPOLÓGICAS DE LA AMAZONÍA Y DE LOS ANDES PERUANOS, 1938-1948
}

\section{[M. KUCZYNSKI-GODARD (1890-1967): MEDICAL-ANTHROPOLOGICAL PICTURES OF THE PERUVIAN AMAZON AND THE ANDES, 1938-1948]}

Michael Knipper ${ }^{1, a}$, Oswaldo Salaverry 2,3,a
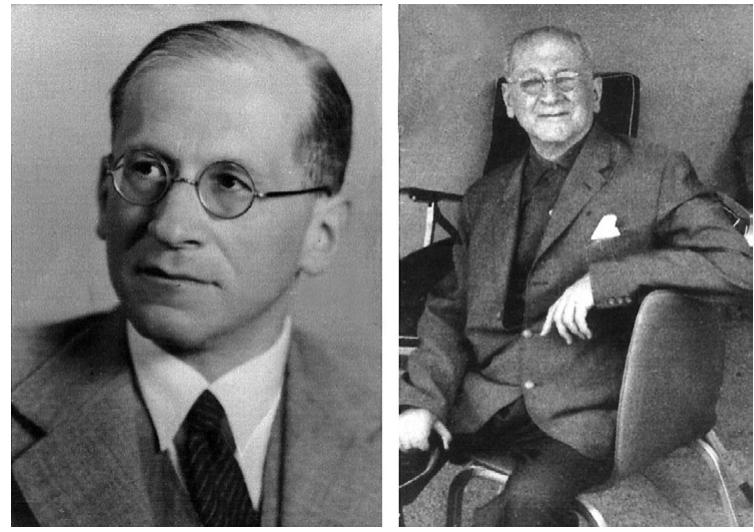

Figura 1. Máxime Kuczynski-Godard.

Entre 1938 y 1948, el médico alemán nacionalizado peruano, Máxime Kuczynski-Godard (Berlín 1890 - Lima 1967), desarrolló su labor de patólogo y salubrista en las zonas rurales de la Amazonía y de los Andes peruanos ${ }^{(1-3)}$. Como miembro del Instituto de Medicina Social de la Universidad Nacional Mayor de San Marcos y apoyado por el ilustre director-fundador de esta institución, Prof. Carlos Enrique Paz Soldán (1885-1975), KuczynskiGodard realizó estudios detenidos del estado de salud de los pobladores tanto indígenas como campesinos y colonos. Empezó su trabajo en la Amazonía en la "Colonia de Perené", enclave británica de producción agraria. A partir de 1940 dirigió la "Supervisión Sanitaria del Nor-Oriente Peruano" por encargo del Ministerio de Salud Pública y Asistencia Social, con sede en lquitos ${ }^{(4-7)}$. Desde 1944 a 1948, trabajó como asesor técnico del Ministerio en varias investigaciones médico-sociales en la parte sur de los Andes ${ }^{(8-10)}$

En muchas de las publicaciones que resultaban de estos trabajos, Kuczynski-Godard solía incluir láminas fotográficas para la documentación visual de sus observaciones. En las fotografías se ponen de relieve un aspecto distintivo de su perspectiva médica-científica y de la manera de trabajar de este patólogo y salubrista multifacético, que ya se puede encontrar en sus primeras expediciones médicas a las estepas de Asia Central que entre 1923 y 1925: la gran importancia que tenía para M. Kuczynski Godard el trabajo de campo y la convivencia directa con los habitantes de las zonas en estudio ${ }^{(11,12)}$.

Para conocer a fondo los problemas médicos de las distintas poblaciones y determinar estrategias sanitarias adaptadas al medio y sus habitantes, Kuczynski-Godard empleó metodologías de investigación muy diversas: analizó las condiciones geográficas y el clima, realizó estudios de antropología física, registró meticulosamente la situación socioeconómica de pueblos, calles, casas y familias, y analizó los hábitos alimenticios y de higiene. Practicó lo que algunos años más tarde en la antropología social y cultural se iba a llamar "observación participativa", pero con un enfoque claramente médico. Utilizó todos los recursos teóricos y metodológicos que había adquirido durante la primera etapa de su vida

\footnotetext{
Instituto de Historia de la Medicina, Justus-Liebig-Universität. Giessen, Alemania.

2 Centro Nacional de Salud Pública, Instituto Nacional de Salud. Lima, Perú.

3 Facultad de Medicina, Universidad Nacional Mayor de San Marcos. Lima, Perú.

a Médico, Doctor en Medicina.
} 


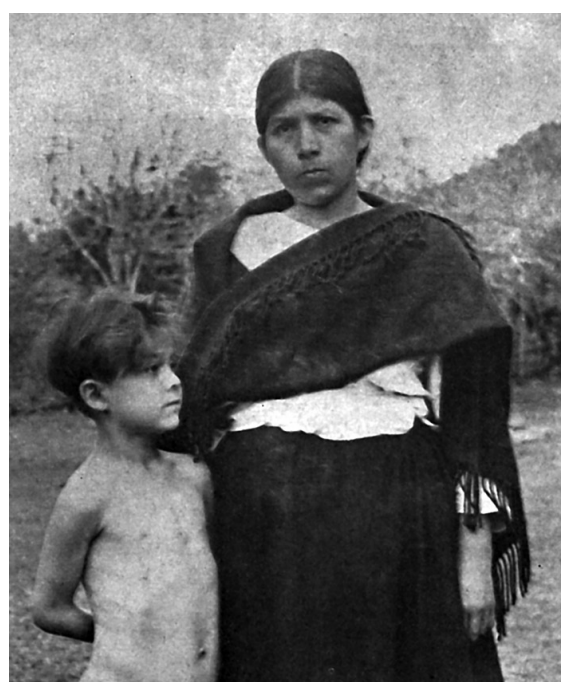

Figura 2. "La madre india con su hijo rubio, de ojos azules, que guarda, más o menos, el tipo de su padre, de ascendencia espanola (vándala). Valle de Guayabamba, departamento de Amazonas. Es una ilustración viva del "crisol de razas", que es la población de estas comarcas" (8).

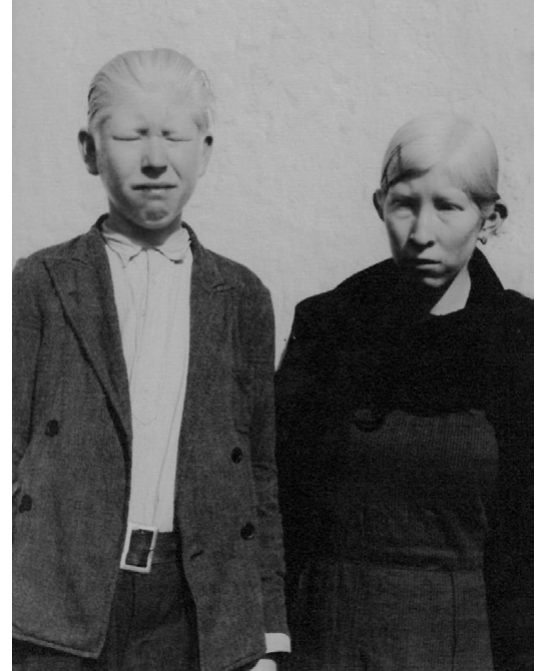

Figura 3. Jóvenes de descendencia europea con albinismo (Amazonía).

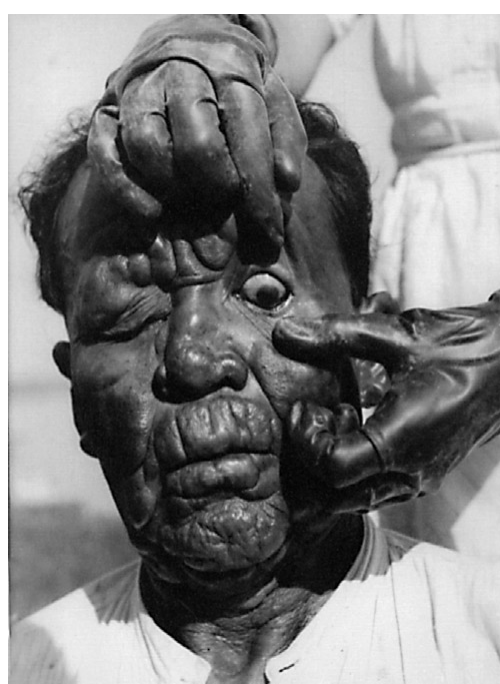

Figura 4. Paciente con lepra en la colonia de San Pablo ${ }^{(7)}$. científica, en Alemania. Tenía un doctorado en filosofía y ciencias con una tesis en parasitología (Universidad de Rostock, 1913) y otro en medicina, realizado en el Instituto de Patología de la Universidad de Berlín (1919).Hasta su emigración forzosa en 1933 emprendió una prometedora carrera científica y de docente en esta misma institución $y$ fue nombrado profesor $y$ jefe de jefe del departamento de bacteriología en 1923. Además, realizó estudios de antropología física y cultural (1908-1912) con el célebre médico, antropólogo y primer catedrático de etnología de la Universidad de Berlín, Felix von Luschan (1854-1924).

Las fotografías seleccionadas para la presente galería, representan cuatro ámbitos temáticos esenciales de la obra médica y antropológica de Máxime KuczynskiGodard:

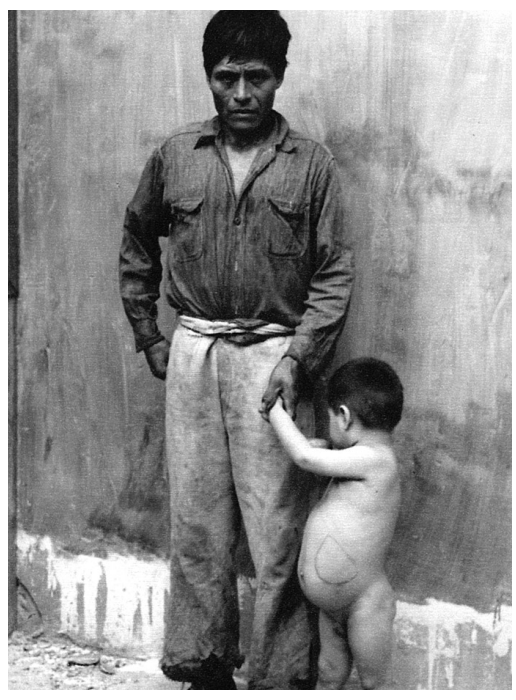

Figura 5. Desnutrición infantil, parasitismo. Obsérvece el tamaño del bazo dibujado sobre la piel del niño.
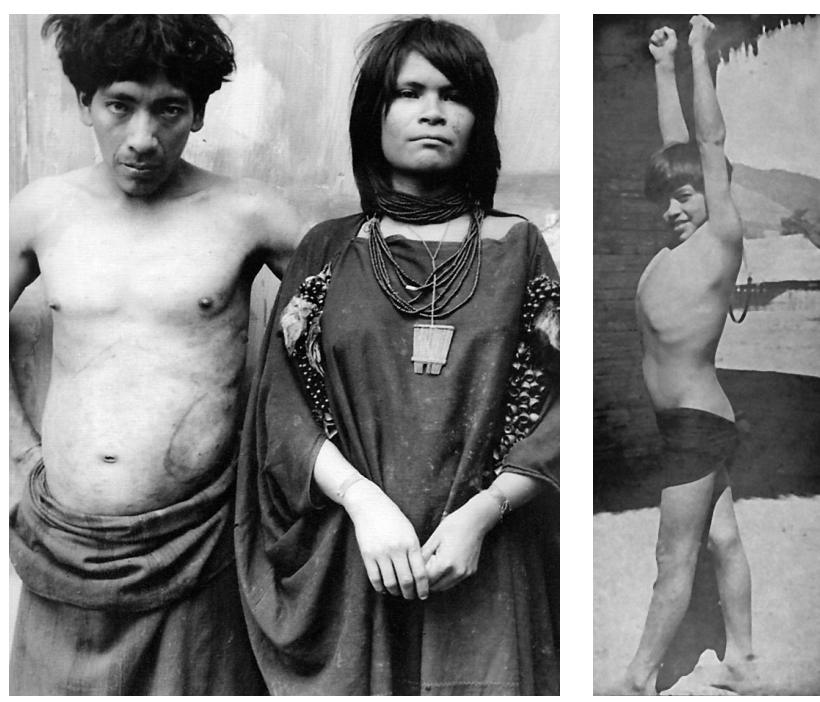

Figura 7. "Hijo del jefe Manioco (del rio Pichinaqui-Perené). Familia de Indios independientes. Muestra la calidad física superior de los jóvenes católicos, es decir, de la gente que vive la antigua vida natural” (5).
Figura 6. Pareja de "Campas" probablemente de la colonia de Perené ${ }^{(5)}$. Obsérvece también aqui el tamaño del bazo dibujado sobre la piel del hombre. 


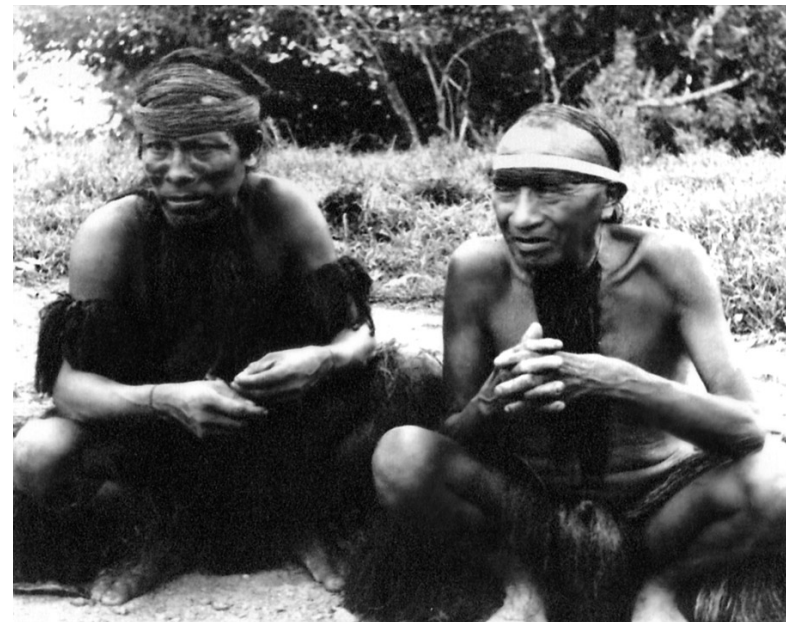

Figura 8. Adulto y anciano "Yagua" (archivo personal PPK).

1. La antropología física. Con imágenes de personas que según el fotógrafo presentan rasgos físicos que permiten identificar la ascendencia de un individuo de ciertos grupos de habitantes tradicionales o colonos, sobre todo en la Amazonía. El enfoque está en el tema del mestizaje genético, con lo cual Kuczynski-Godard demuestra con nitidez la influencia de su profesor de antropología, Felix von Luschan. Sin embargo, la obra

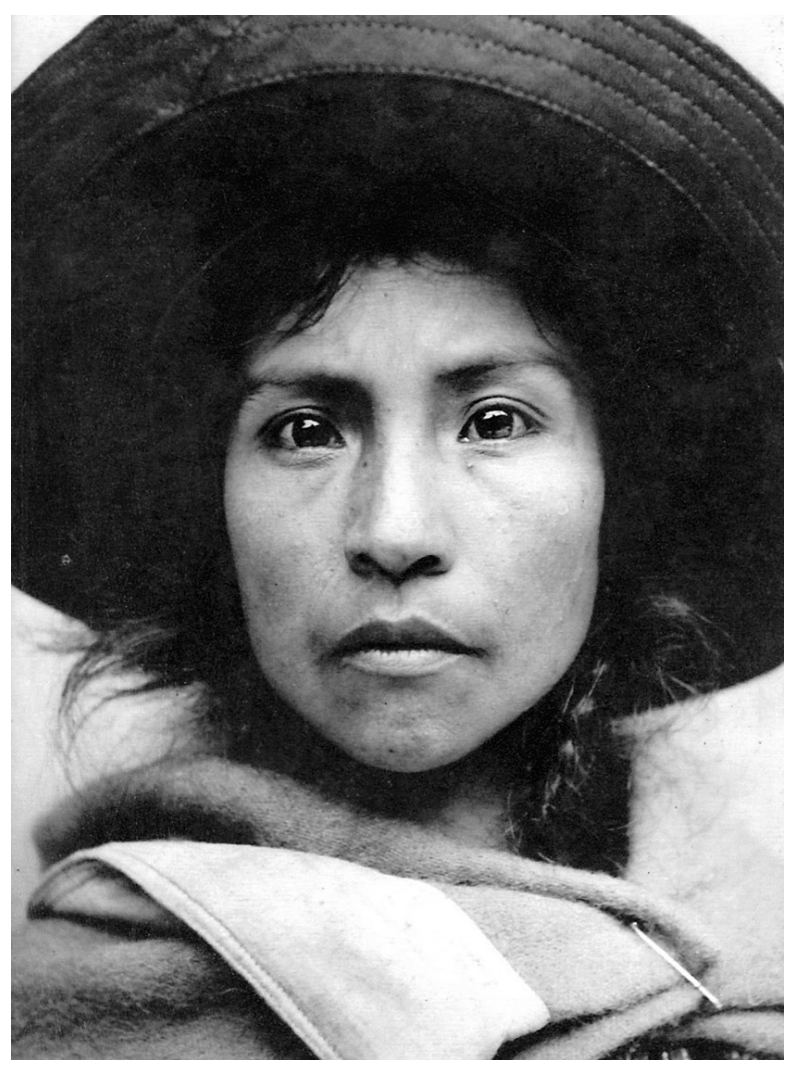

Figura 10. Retrato de joven andina.

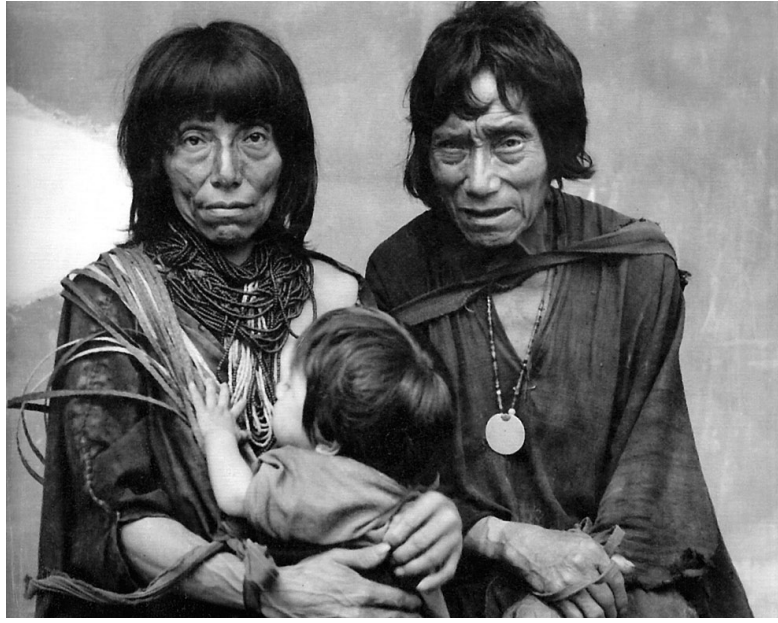

Figura 9. Familia Campa.

de ambos se distingue por el rechazo de conceptos contemporáneos que suponían la existencia de diferentes "razas" humanas y que relacionaron rasgos físicos o "raciales" con el carácter o las calidades físico o mentales de las personas.

2. Salud y enfermedad. Muchas fotografías son documentaciones de enfermos con cuadros

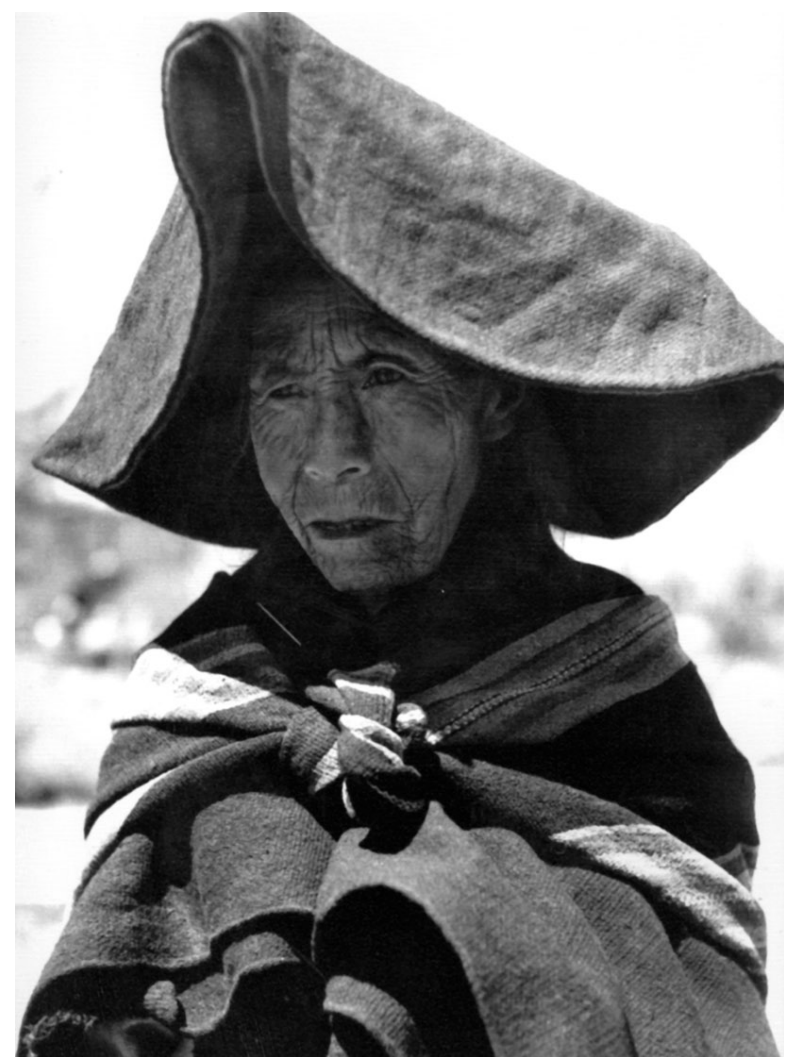

Figura 11. Retrato de mujer en traje típico. 


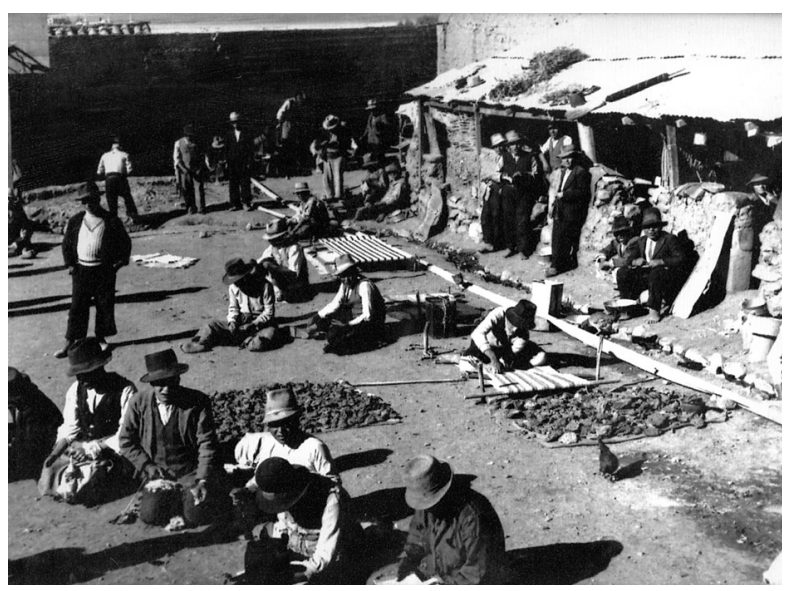

Figura 12. Vista de la cárcel de Puno, llave $1944^{(9)}$.

patológicos específicos, que Kuczynski-Godard encontró en las poblaciones tanto de la Amazonía y de los Andes. En algunas imágenes, se combina el interés médico con la mirada del etnólogo, que se fija por ejemplo en la vestimenta y la identidad étnica de los enfermos. Otras fotografías demuestran, sin embargo, personas sanas. En las leyendas correspondientes, el médico atrás de la cámara a menudo ofrece consideraciones acerca del buen estado físico y de alimentación de estas personas, como para demostrar el objetivo y la viabilidad de sus esfuerzos médico-sociales para un "porvenir más feliz" ${ }^{(7, p .36)}$ en la Amazonía y en los Andes.

3. Medicina social. En una cita emblemática y muchas veces citada, Kuczynski-Godard expresa su convicción de que /...El médico para ser lo que debe ser no puede limitarse a hacer curaciones, a esperar que se le presenten los enfermos; ha de penetrar el medio; ha de interesarse por todos los aspectos de la vida

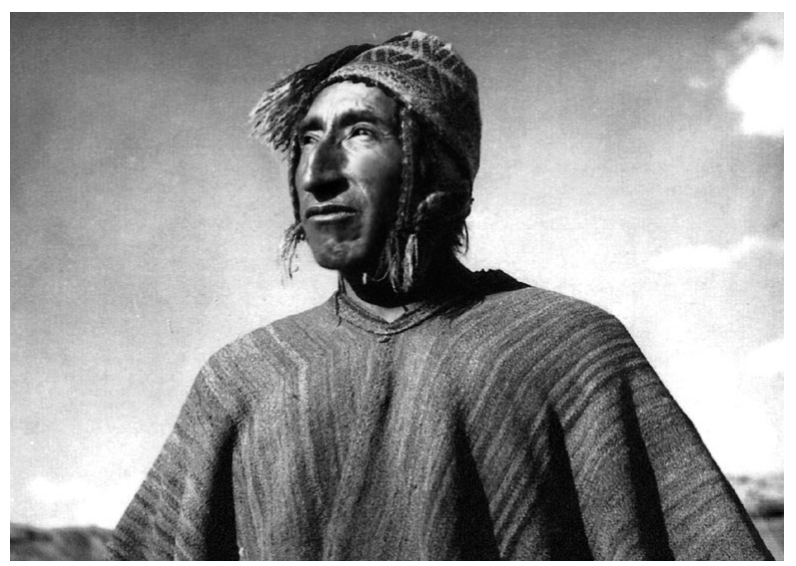

Figura 14. "Dignidad indígena".

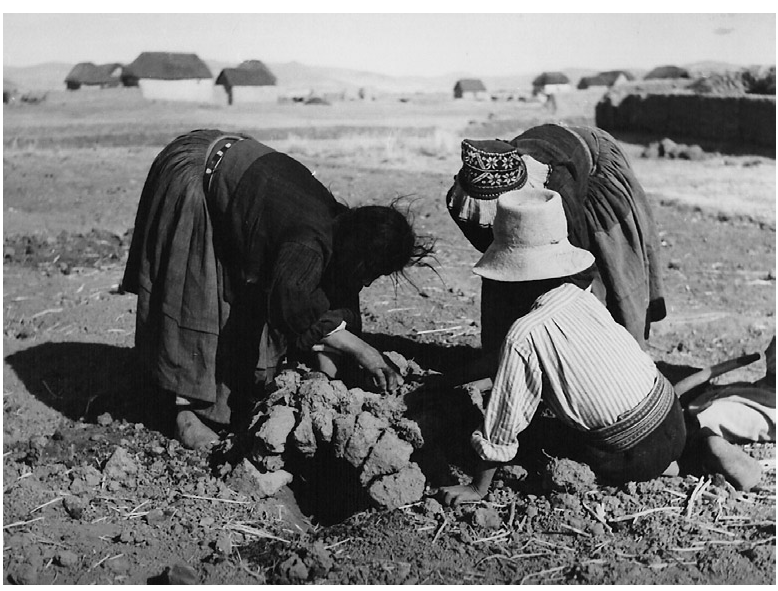

Figura 13. La "casa de huattias" o "huaja--uta", horno transitorio de terrones para asar papas ${ }^{(9)}$.

del pueblo cuya protección es su propósito.../(7, p. 104) Estas imágenes indican a qué se refiere: al interés en las condiciones de vida particulares de cada familia o grupo poblacional, para llegar a conocimientos adecuados en lugar de consideraciones y juicios superficiales sobre por ejemplo "indios" y "colonos" en general, pronunciados desde la distancia. En varias ocaciones, Kuczynski-Godard critica la

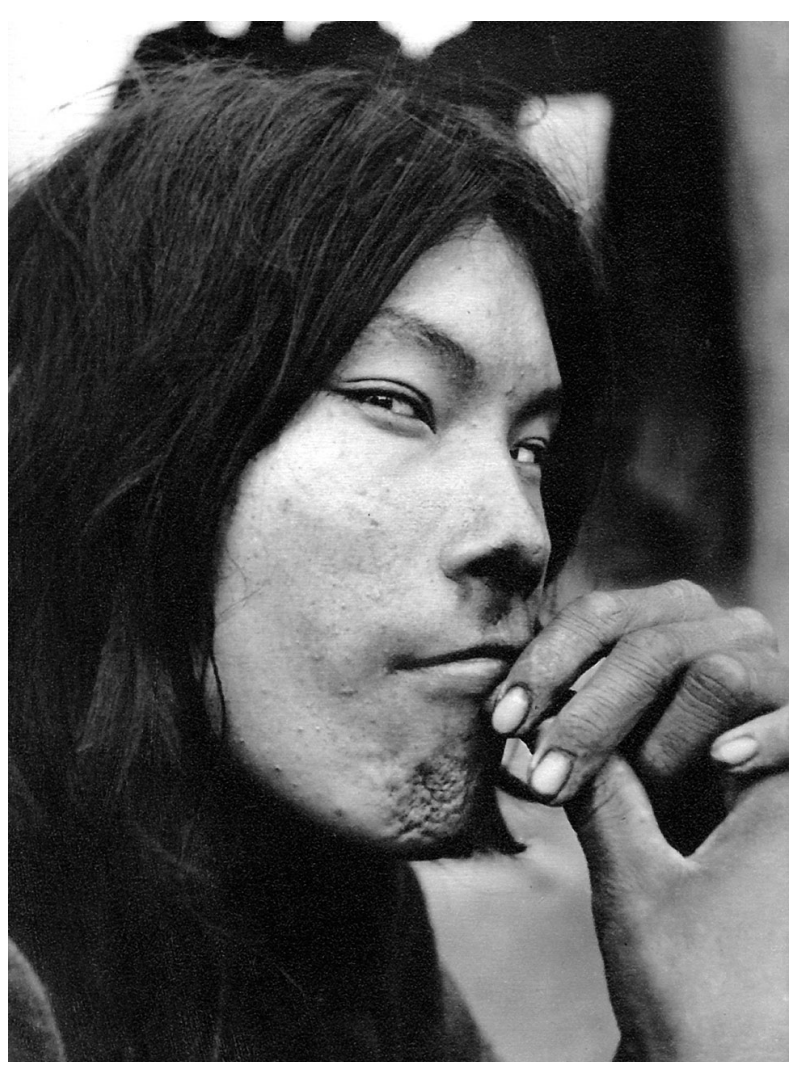

Figura 15. Retrato de indio "ladino". 
distancia que separa el gobierno y las instituciones de las poblaciones rurales, la fotografía además es el medio idóneo para demostrar estas realidades, por ejemplo en la capital.

4. Retratos. Varias imágenes están sin relación con cuestiones médicas o antropológicas. Son retratos de personas, en grupo o individuales, algunos con vestimenta tradicional indígena. Estas fotografías impresionan por la manera como captan las miradas de los individuos o los ambientes retratados. Tal como con la publicación del autobiográfico de una paciente de lepra ${ }^{(13,14)}$, estas fotografías expresan un principio básico de la obra de Máxime KuczynskiGodard desde los inicios de su carrera en Alemania, la perspectiva del humanista, que percibe a toda persona como individuo con dignidad y derechos, independiente de categorías étnicas, sociales y económicas.

\section{AGRADECIMIENTOS}

Expresamos nuestros profundos agradecimientos al Dr. Pedro Pablo Kuczynski-Godard y a Nancy Lange, por el acceso al amplio legado fotográfico de Máxime Kuczynski-Godard y al archivo personal de la familia. Además agradecemos a Marcos Cueto, por su gran labor y constante colaboración en las investigaciones acerca de vida y obra de M. Kuczynski-Godard.

\section{REFERENCIAS BIBLIOGRÁFICAS}

1. Cueto M. Social medicine in the Andes. En: RodriguezOcaña E, ed. The politics of the healthy life. An international perspective. Sheffield: European Association for the History of Medicine and Health Publications; 2002. p. 181-96.

2. Cueto M. Social medicine and "Leprosy" in the Peruvian Amazon. The Americas. 2004; 61(1): 55-80.

3. Knipper M. "Nuevas tareas médicas en la nueva Rusia" (1924): La visión de 'patología étnica' y medicina científica de Max Kuczynski en los años anteriores a su emigración al Perú. An Fac Med (Lima). 2005; 66(3): 247-54.
4. Knipper M.Antropología y "crisis de la medicina”: el patólogo M. Kuczynski-Godard (1890-1967) y las poblaciones nativas en Asia Central y Perú. DYNAMIS. 2009; 29: 97-121.

5. Kuczynski-Godard, MH. La Colonia del Perené y sus problemas médico sociales. Lima: Ediciones de "La Reforma Médica"; 1939

6. Paz Soldán CE, Kuczynski-Godard, MH. La selva peruana. Sus pobladores y su colonización en seguridad sanitaria. Lima: Ediciones de "La Reforma Médica"; 1939.

7. Kuczynski-Godard, MH. San Pablo. Actualidad y porvenir. Un informe sobre la reorganización de la Colonia con apuntes sobre la sociología médica de la lepra en e oriente amazónico. Lima: Imprenta Lux; 1942.

8. Kuczynski-Godard MH. La vida en la Amazonía peruana. Observaciones de un médico. Lima: Liberería Internacional del Perú; 1944.

9. Kuczynski-Godard MH. La Pampa de llave y su Hinterland. Lima: Ministerio de Salud Pública y Asistencia Social; 1944.

10. Kuczynski-Godard, MH. Estudios médico-sociales en las minas de Puno con anotaciones sobre las migraciones indígenas. Lima: Ministerio de Salud Pública y Asistencia Social; 1945.

11. Kuczynski-Godard, MH. En orden al potencial humano del Perú. Observaciones y Reflexiones (con 12 diagramas y 33 ilustraciones). Estudios e investigaciones realizados por la Comisión Ejecutiva del Inventario del Potencial Económico de la Nación, fascículo segundo. Lima: Sanmarti \& Co.; 1949/1950.

12. Kuczynski MH. Steppe und Mensch. Kirgisische Reiseeindrücke und Betrachtungen über Leben, Kultur und Krankheit in ihren Zusammenhängen. Leipzig: Hirzel; 1925.

13. Kuczynski-Godard MH. Vida de leprosa. Narraciones médico-sociales extraordinarias. Lima: Ediciones de "La reforma Médica"; 1947.

14. Cueto M, Puente JC. Vida de leprosa: testimonio de una mujer viviendo con la enfermedad de Hansen en la Amazonía peruana, 1947. Hist Cienc Saude Manguinhos. 2003; 10(suppl.1): 337-60.

Correspondencia: Oswaldo Salaverry

Dirección: Capac Yupanqui 1400, Lima 11, Perú.

Teléfono: (511) 617-6200 Anexo: 1609

Correo electrónico: oswaldosalaverry@gmail.com 